\title{
Oil Vulnerability in the Australian City: Assessing Socioeconomic Risks from Higher Urban Fuel Prices
}

\author{
Jago Dodson and Neil Sipe \\ [Paper first received, January 2006; in final form, April 2006]
}

\begin{abstract}
Summary. Global oil prices have risen markedly over the past 18 months, generating considerable speculation regarding their economic and social impacts. Cities that are highly dependent on petroleum for urban transport are likely to be most adversely affected by rising oil prices. Yet there has been little recent scholarly engagement with the socioeconomic implications of increasing oil prices. This paper develops a basic framework and methodology for assessing the socioeconomic 'oil vulnerability' of Australian cities. The paper demonstrates that there is wide spatial variability in the vulnerability of Australia's urban populations to rising fuel costs which may compound existing socio-spatial divisions and speculates on some underlying causal factors. The paper calls for better data and new methods to understand the issue.
\end{abstract}

\section{Introduction}

A large body of literature has been generated in recent years that considers how economic and social restructuring processes have impacted on cities and the new socio-spatial patterns that have emerged. Much attention has been directed to such phenomena as divided cities (Fainstein et al., 1992), socioeconomic polarisation (Hamnett, 1994), socio-spatial segregation (Madden, 2003) and social marginalisation (Wacquant, 1999). The role of housing (Lee, 1994) and labour (Walks, 2001) markets in mediating and influencing these shifts has been particularly prominent, while various other contributing factors such as housing subsidies (Hills, 2001), welfare provision (Wessel, 2000) and transport systems (Hamilton and Jenkins, 2000) have also been evaluated as to their role in exacerbating or ameliorating exclusionary urban processes.
To date, however, there has been relatively little scholarly contemplation of the links between transport systems and socio-spatial patterns. While some researchers have considered the role that transport plays in social exclusion (Lucas, 2004; Hine and Mitchell, 2001) or labour market frictions (Martin, 2001), there have been few studies that directly contemplate the connections between the costs of transport, socioeconomic status and urban spatial differentiation. In particular, the link between automobile dependence, household socioeconomic status and spatial differentiation at the metropolitan scale has not been extensively considered. We argue in this paper that these issues deserve substantial and urgent consideration from scholars given the current uncertainty about the price of oil and the economic and social impacts that rising oil prices could 
entail for cities that are dependent on cheap fuel. Of critical importance is how the impact of recent and future oil prices rises might be distributed across urban areas and which social groups and localities would be most adversely affected. Could oil dependence mark a new dimension of socio-spatial division in cities?

The international price of oil has increased markedly in recent months and considerable uncertainty exists about the future direction of oil prices. While many observers argue that these recent high prices will soon decline, a substantial body of commentary suggests that current prices are likely to continue for some time with possible future increases. Some point to potential supply problems that in combination with increasing demand for oil could drive oil prices even higher. Higher fuel costs have substantial implications for cities given that urban transport systems are heavily dependent on petroleum.

This paper examines three Australian cities to assess the distribution of socioeconomic 'oil vulnerability'. The paper asks how sociospatial and transport mode patterns intersect in Australian cities and how socioeconomic vulnerability to oil price rises is distributed across Australian cities. The paper comprises three parts. First, the paper considers the global context for petroleum availability and supply to establish that oil vulnerability is an issue that deserves social scientific consideration. Next, the paper assesses the spatial distribution of oil dependence in Australian cities in terms of reliance on automobile transport for urban travel and identifies how these are currently known to intersect with spatial socioeconomic patterns. Thirdly, the paper reports an empirical analysis of spatial 'oil vulnerability' in Australian cities-Sydney, Melbourne and Brisbane-via a methodology for assessing socioeconomic exposure to rising oil prices, at the local neighbourhood scale. The analysis we present suggests that any socioeconomic impacts from rising fuel costs would be highly unevenly distributed across Australian cities. The paper concludes with some observations regarding the need for further and broader social scientific consideration of this issue both in Australia and internationally, in the context of existing knowledge of urban socio-spatial processes.

\section{Rising Oil Prices}

One thing is clear: the era of easy oil is over (Chevron Oil Ltd advertisement, The Economist, 16 July 2005, pp. 6-7)

One of the most noted global economic phenomena over the past 18 months has been the strong and relatively rapid increase in the international price of oil. The global price of crude oil rose from approximately US\$30 per barrel in early 2004 to a high of US\$70 in September 2005 (Figure 1). The early months of 2006 have seen international oil prices remain above US\$60 per barrel. Rising international oil price rises have produced domestic fuel price increases in most nations. Petrol prices rose at least 16 per cent across Europe during 2005 (Table 1) while most European countries have experienced petrol price increases of at least 20 per cent with some higher than 30 per cent.

Australia has not avoided these price pressures. The Australian Bureau of Statistics reports that the cost of 'automotive fuel' in Australia rose approximately 10 per cent during the year to June 2005, with an increase of 7.2 per cent during the June 2005 quarter (ABS, 2005a) and a further 11.6 per cent during the September quarter (ABS, 2005b). This pattern was reflected in the retail cost of fuel. Petrol prices in Sydney rose 40 per cent between January 2004 and September 2005 (Figure 2), a pattern that was replicated in other Australian capitals. Australian petrol prices have eased from their September 2005 highs of above AU\$1.26/litre but remain well above historical levels. At the time of writing, average Sydney petrol prices remain around AU\$1.15/litre. There are no indications of a short-term decline in international oil prices which continue to fluctuate between US\$60 and US\$70 per barrel.

\section{Underlying Pressures}

There is a reasonable degree of consensus regarding the drivers of the recent 


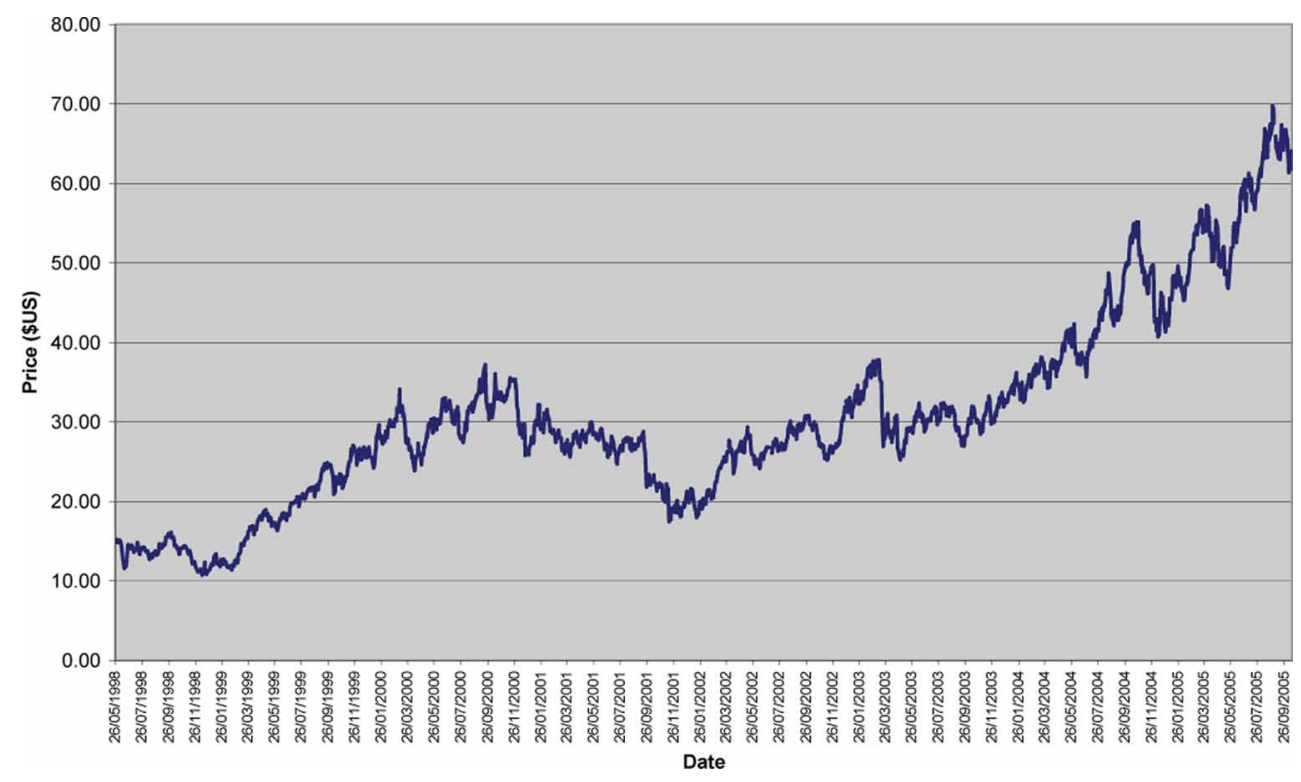

Figure 1. Prices for NYMEX sweet light crude oil (daily contract 1), 1998-2005. Source: US Department of Energy (2005).

international oil price increases. The twin pressures on the international oil price have been reported as including overall global economic growth, particularly new demand from China-and to some extent Indiawhich has increased overall global demand for oil. In addition to this strong growth in demand, various supply interruptions have impacted global petroleum production, constraining international supply.
In Australia, the causes of the recent high petrol prices have been the subject of much public debate between motorist lobby groups, oil companies, regulators and politicians. The National Roads and Motorists Association $^{1}$ has claimed that oil companies have been 'gouging' prices (Baker, 2005), while the Australian Consumer and Competition Commission has argued that current prices merely reflect international patterns

Table 1. Fuel price changes in selected European countries, January-September 2005

\begin{tabular}{lccccc}
\hline & \multicolumn{2}{c}{ Fuel price } & & $\begin{array}{c}\text { Monetary } \\
\text { unit }\end{array}$ & $\begin{array}{c}\text { Percentage } \\
\text { increase }\end{array}$ \\
\cline { 2 - 3 } Country & January 2005 & September 2005 & & $€$ & 32.6 \\
Austria & 0.89 & 1.18 & $€$ & 29.5 \\
Belgium & 1.12 & 1.45 & & $€$ & 26.0 \\
France & 1.04 & 1.3 & & $€$ & 27.4 \\
Germany & 1.06 & 1.35 & & $€$ & 36.0 \\
Greece & 0.75 & 1.02 & & $€$ & 16.9 \\
Netherlands & 1.24 & 1.45 & & $€$ & 19.2 \\
Ireland & 0.99 & 1.18 & & $€$ & 22.2 \\
Italy & 1.08 & 1.32 & & $K r$ & 21.4 \\
Norway & 10.05 & 12.20 & & $€$ & 29.8 \\
Spain & 0.84 & 1.09 & & $S F r$ & 26.3 \\
Switzerland & 1.37 & 1.73 & & $£$ & 19.1 \\
UK & 79.6 & 94.78 & &
\end{tabular}




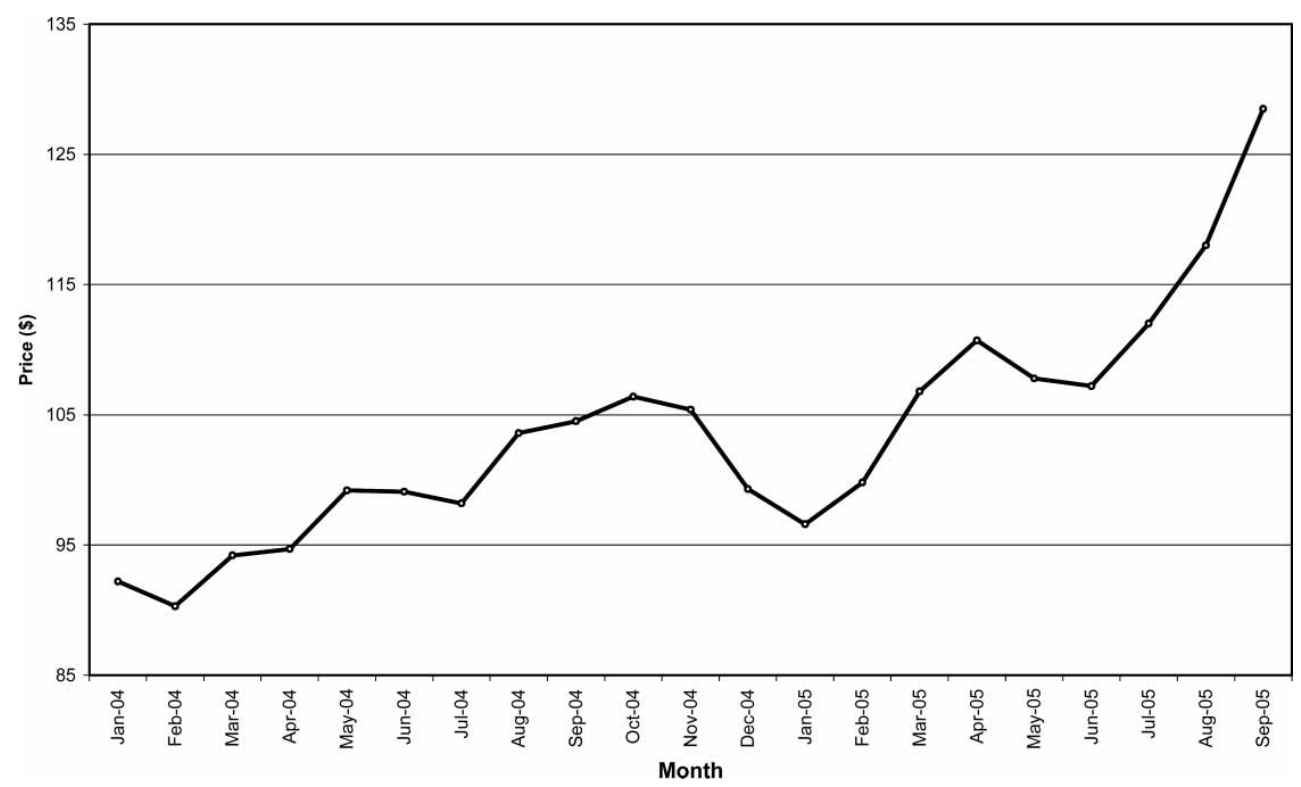

Figure 2. Monthly average fuel price for Sydney, 2004/05. Source: AC Nielson (2005, p. 3, chart 1).

of supply and demand combined with international currency exchange rate fluctuations (ACCC, 2005).

A number of Australian political representatives have acknowledged that oil prices are likely to remain at least at their present level. Prime Minister John Howard (2005) has publicly admitted that "We're not going to go back to the days of having petrol below a dollar a litre for quite some time, if at all." The Queensland State government and the Australian Senate have instigated separate inquiries into the causes of oil price rises and the security of future oil supplies respectively (see for example, Senate Rural and Regional Affairs and Transport Committee, 2005).

\section{An Oil Production Peak?}

The pressure on oil prices has drawn substantial attention to the longer-term outlook for petroleum production. A number of credible scholarly analyses suggest that global oil production will peak within the next 20 years (Deffeyes, 2001; Campbell, 2003). 'Peak oil' is the point where approximately half of all the world's oil supplies have been consumed and implies a growing gap between expanding petroleum demand and a gradually declining oil supply.

Peak oil has major implications for cities that are dependent on a continuing supply of cheap oil for economic activity and growth. The impact of this potential growing shortfall between petroleum demand and supply is currently the subject of much controversy among industry analysts (Deffeyes and Huber, 2005). Many commentators argue that market forces will limit the price impact of peak oil by driving advances in technology and extraction techniques as well as through improvements in the efficiency of oil consumption (Huber and Mills, 2004; Cable, 2005). A group of more pessimistic analysts and commentators, such as members of the Association for the Study of Peak Oil and Gas (Campbell, 2005), argues that there are few alternative sources of energy that can provide the same energy return on energy invested ratio as petroleum and that few substitutes for conventional oil are available.

Scholarly observers have drawn attention to the potential adverse scenarios that peak oil portends for cities that are dependent on private motor vehicles for urban mobility. 
Newman's (1991) and Newman and Kenworthy's $(1989,1999)$ work has been prominent in warning about the levels of automobile dependence in cities, particularly those of the US and, to a comparable albeit lesser extent, Australia. Fleay's (1995) work provided an early but comprehensive engagement with the urban implications of peak oil. Research-based empirical analyses of how petroleum scarcity scenarios could impact on cities remain rare, however, either in Australia or internationally.

Some speculation into the urban impacts of oil insecurity has pointed to broader and deeper impacts than simply increased fuel costs and which could extend into every aspect of urban economic and social life (Heinberg, 2004; Kunstler, 2005). While sprawling car-dependent US suburban areas have been of great concern for these authors, their assessments are not typically based on detailed empirical data.

Fleay (1995), Newman and Kenworthy (1999) and Robinson and Powrie (2004) are the only scholars to have considered the implications of oil insecurity for Australian cities to any substantive extent. However, their analysis has largely been from a broad and general view with limited attention to the specifically socioeconomic impacts of petroleum scarcity, or to the spatial distribution of impacts across Australian cities.

We are not petroleum scholars and do not wish to comment on the validity of the concept of peak oil or on the likelihood of its occurring. However, we consider that it is imperative for social scientists to begin contemplating the risk that either a rising oil price or oil peak scenario might pose for urban economic and social systems. The remainder of the paper begins this task by investigating the extent to which Australian urban areas depend on petroleum and by assessing the spatial distribution of socioeconomic impacts arising from increased fuel costs.

\section{Urban Transport and Energy}

Within the international context, US cities are, on average, the most car-dependent, when compared in aggregate with Canadian, Australian, European or Asian cities (Table 2). US cities consume more energy supporting private passenger travel than other cities, while the dependence of US cities on private automobiles for urban travel is also greater than comparators. While they are not as dependent on automobiles as most US cities, Australian cities are nonetheless highly cardependent and thus oil-dependent (Newman, 1991), as indicated by the energy use levels in Table 2. Australian urban car dependence is greater than most comparable Canadian, European or Asian cities. The private motor car is used for the vast majority of all types of trips in most Australian capital cities

Table 2. Selected indicators of automobile dependence for cities

\begin{tabular}{lcccccc}
\hline & \multicolumn{5}{c}{ Average value for cities } \\
\cline { 2 - 7 } Indicator & US & Australia & Canada & Europe & Wealthy Asia & Developing Asia \\
\hline $\begin{array}{c}\text { Private passenger } \\
\text { energy use (MJ/ } \\
\text { capita) }\end{array}$ & 55807 & 33562 & 30893 & 17218 & 7268 & 6819 \\
$\begin{array}{c}\text { Total private } \\
\text { vehicle km per } \\
\text { passenger }\end{array}$ & 12336 & 8034 & 7761 & 5026 & 2950 & 2337 \\
$\begin{array}{c}\text { Percentage of } \\
\text { workers using } \\
\text { private transport }\end{array}$ & 86.3 & 80.4 & 74.1 & 42.8 & 20.1 & 43.9 \\
\hline
\end{tabular}


(Newman and Kenworthy, 1999; Mees, 2000a; Morris et al., 2002).

Given that this paper is concerned about the socioeconomic vulnerability of our cities to increasing fuel costs it is worth identifying some of the specific travel patterns that contribute to this vulnerability. This discussion also identifies crucial Australian intraurban differences in transport patterns that are likely to have socioeconomic implications should fuel costs increase.

\section{Travel Patterns}

In a groundbreaking study Newman et al. (1985) demonstrated that households in outer metropolitan areas of Australian cities are typically more car-dependent and thus use more transport energy, on average, than inner-city residents. This study, however, was based on 1976 travel survey data. Contemporary travel patterns suggest little divergence from those identified by Newman et al. (1985) and indicate possible greater spatial differentiation in car dependence. Sydney, which maintains high-quality current survey data, exemplifies the increasing level of car dependence of Australian cities and the spatial travel behaviour patterns associated with this phenomenon. Approximately 15 million trips are undertaken each day in Sydney, 70 per cent of which are by car (DIPNR, 2003). Sydney's annual total vehicle kilometres travelled (VKT) increased, on average, 2.3 per cent each year from 1991 onwards-faster than population growthrising to approximately 80 million kilometres in 2001 (DIPNR, 2005). As is found in other Australian cities, these patterns were geographically highly uneven; per-person VKTs increased by approximately 23 per cent in the modest- and low-income suburbs of outer and south-west Sydney, but declined by 10 per cent in the wealthier inner and east Sydney areas. There is therefore strong socioeconomic variation in the use of motor vehicles by Sydney's population. Similar travel patterns are likely to be found in other Australian cities (Newman et al., 1985; Morris et al., 2002]

\section{Modal Imbalance}

Inadequate public transport combined with an on-going policy emphasis on major road programmes is the main cause of Australian car dependence. Australia's public transport systems are beset by operational and patronage problems with many operating below potential capacity (Mees, 2000a). Modal integration is typically poor and the use of local buses to feed the higher-capacity rail systems is underdeveloped (Mees, 2000a). The lack of circumferential links between the radial rail lines limits the use of public transport for dispersed middle and outer suburban trips. Institutional fragmentation compounds service deficits and limits the institutional strength of state public transport agencies relative to state road departments.

While public transport systems have languished in recent years, state governments in Australia have undertaken comparatively high levels of new investment in major road networks. In Sydney, a number of tollways have been constructed that have encouraged the use of private motor vehicles for urban travel (Zeibots, 2003). Melbourne in the 1990s constructed the CityLink tollway system and the Western Ring Road, while the largest current transport infrastructure project there is the AU $\$ 2.5$ billion outer eastern Scoresby Tollway. Brisbane's largest proposed transport project is an AU\$8 billion suite of five tunnels known as 'TransApex'.

These road projects have entrenched and exacerbated high levels of car dependence among urban travellers in Australian cities (Mees, 2000a) by drawing patronage away from public transport, increasing congestion and decreasing the viability of public transport systems (Zeibots, 2003). This mass automobile dependence is in large part possible because of the availability of relatively cheap petroleum. Australia's automobiledependent cities risk adverse social and economic outcomes due to rising oil prices. Urban residents at the lower end of the socioeconomic spectrum are likely to be the worst affected because they tend to be more 
dependent on the motor car and have limited capacity to absorb additional costs not only for travel but also for generalised fuel-driven price increases.

\section{Transport and Socioeconomic Disadvantage}

Transport disadvantage is a critical issue in Australia's cities. In addition to being highly car-dependent, Australian cities are marked by strong spatial socioeconomic differentiation. Recent economic and social restructuring has created an urban geography in which higher-income groups are largely concentrated within inner locations and the most highly disadvantaged households are situated in middle or outer suburban localities (Maher, 1994; Murphy and Watson, 1994; Wulff and Evans, 1999; Wulff and Reynolds, 2000; Yates, 2002a, 2002b; Baum et al., 2005).

Access to transport services appears to be a key delineator of socioeconomic status within Australian cities (Cheal, 2003; Dodson, 2004; Dodson et al., 2004). The combination of residential geography, socioeconomic status and transport system access has enabled high socioeconomic status households to locate in areas with better-quality public transport services, while lower socioeconomic status groups in fringe areas receive much poorer services (Mees 2002a, 2002b; Morris et al., 2002; Cheal, 2003).

Qualitative studies have demonstrated the impact on households' socioeconomic opportunities arising from transport disadvantage internationally and in Australia. Research in the UK, for example, has demonstrated that access to employment, health services, education and recreation are all impeded by inadequate transport, particularly for lower socioeconomic status groups (SEU, 2002, 2003; Lucas, 2004). There is little Australian research that depicts the impact of transport disadvantage or transport stress at the local scale. Johnson and Herath's (2004) insightful qualitative study of two socioeconomically disadvantaged outer Brisbane suburbs found that the residents were not only poorly served by public transport and local pedestrian and cycling infrastructure, but that the adjacent motorway and rail networks compounded social disadvantage by impeding spatial access to social, health and community services and, crucially, to employment.

Some Australian literature has examined the issue of 'locational disadvantage' arising from household locational decisions to move to fringe areas (Maher et al., 1992; Maher, 1994). Modest-income households entering Australian housing markets often locate in outer suburban areas that have a supply of relatively cheap new dwellings (Burnley et al., 1997). Maher et al. (1992) argued that these households risk being locationally disadvantaged in terms of the facilities and resources necessary to enable a 'satisfactory life' because they experience long journeys to access such resources. The transport network and transport services are key elements of locational disadvantage.

Australian households face a residential trade-off in their housing choices between their capacity to afford housing versus their distance from the relatively centralised employment and services found in the major cities. Improvements in transport systemsoverwhelmingly road-based and reliant on cheap fuel-have over time flattened the land price-distance gradient thus reducing the relative costs of greater dispersion from urban cores, enabling households to access cheaper land, further from city centres, and thus afford homeownership (Manning, 1984; Burnley et al., 1997). Employment has also partly suburbanised, but is often located away from public transport, thus necessitating car use for access (Neutze, 1977; Dodson, 2005; Goodman, 2005).

Rising fuel costs have implications for the historical trend towards a flatter pricedistance gradient, particularly for those governments and developers whose planning has been based on low petrol prices. Households who have located in the outer and fringe areas of Australian cites may face increasing financial stress due to the combination of high or rising fuel costs and limited transport alternatives. Yet there is little contemporary appreciation in Australia by scholars, governments or 
the development sector of the dynamics of household social status, urban location and travel costs.

\section{Household Transport Stress}

The differential impact of transport costs deserves further reflection. Transport costs are one of the largest items in Australian household budgets (Table 3). Yet, an oftenignored dimension of transport disadvantage in Australian cities is the transport cost burden-'transport stress' (Dodson et al., 2004) - on households and the relative composition and spatial distribution of household transport costs within cities. The concept and measurement of transport stress is a corollary to the concept of 'housing stress' which is a measure used to assess housing affordability (National Housing Strategy, 1991; King, 1994). Households are considered to be in housing stress if they are in the lowest two income quintiles and their housing costs exceed 30 per cent of income (National Housing Strategy, 1991). Transport stress can be defined as the proportion of weekly household income that is expended on transport, whether by motor vehicle, public transport or other mode. There has been no detailed scholarly assessment of transport stress to consider what thresholds or indicators should be used to assess transport stress, but households suffering transport stress could be viewed as those whose income is 40 per cent of the metropolitan median and whose transport costs exceed 20 per cent of their income. Developing better understanding of the extent and spatial distribution of this phenomenon would be an important scholarly and policy response to any further major increases in automotive fuel costs.

Measuring the spatial distribution of household transport stress is not currently possible in Australia because there are no datasets available that include detailed local information on income, transport costs and urban location at the household level. State government travel surveys such as those operating in South East Queensland or Sydney include only demographic, travel and locational data. The Australian government's household expenditure survey (HES) operates at a statistical sample size that cannot meaningfully be decomposed to the level of the individual suburb (Table 3). For example, the 2003-04 HES used a sample size of only 579 households for all of Brisbane which makes meaningful local assessments impossible.

Transport costs, on average, make up around 15.2 per cent of household budgets (Table 3). There is, however, little variation in average household transport spending between the major Australian capital cities, which vary by only 1.8 percentage points, compared with housing, which displays a four-point spread of average costs. In some cities, such as Adelaide, Canberra and Melbourne, transport costs exceed nonmortgage housing costs.

Table 3. Selected costs as a proportion of household income for Australia's major metropolitan areas, 2003-04

Australian capital cities

\begin{tabular}{lccccccc}
\hline & \multicolumn{7}{c}{ Australian capital cities } \\
\cline { 2 - 7 } Proportion of income & Sydney & Melbourne & Brisbane & Adelaide & Perth & Canberra & Australia \\
\hline $\begin{array}{l}\text { Current housing costs } \\
\quad \text { (excluding mortgage }\end{array}$ & 18.0 & 14.4 & 17.7 & 14.6 & 15.6 & 14.0 & 16.2 \\
$\quad \begin{array}{l}\text { principal) } \\
\text { Food and non-alcoholic } \\
\quad \text { beveridges }\end{array}$ & 17.3 & 17.5 & 16.8 & 16.7 & 16.5 & 16.7 & 17.1 \\
$\begin{array}{l}\text { Transport } \\
\text { Sample size }\end{array}$ & 14.8 & 15.2 & 16.2 & 15.4 & 15.3 & 14.4 & 15.2 \\
\hline
\end{tabular}


Standardised average running costs for various motor vehicle types are available from motorist associations. In Melbourne, the average weekly running cost for a small car (1.8 litre engine) in 2005 was approximately AU\$148 per week (RACV, 2005). Methodological limitations prevent such data from being used to generate a detailed picture of household financial transport stress, however, but some limited assessment is possible when considered with household car ownership rates.

Given what is known about average vehicle running costs within Australian cities, car ownership can be used as an indicator of household transport stress. Morris et al. (2002) reported that in Melbourne in 1999 central and inner-city areas had per-household car ownership rates of 1.13 and 1.43 respectively, compared with fringe-area households which had on average 1.9 vehicles per household. Larger household sizes exacerbated these spatial differences in car ownership. Morris et al. (2002) report that in Melbourne car ownership averages 1.6 cars per 4 persons in central-city households, whereas outer-suburban 4-person households own on average 2.39 cars. The difference in transport spending between inner-city and outersuburban 4-person households could thus be as much as AU\$117 (0.79 x \$148) per week (equivalent to AU\$6080 per year) for a small car (RACV, 2005). The actual costs are likely to be even higher given that outersuburban households have higher VKT than inner-city households. Given that public transport services in the fringe areas of Australia's major cities are almost universally of low quality (Mees, 2000a; Dodson, 2003), the available data suggest that Australia's divided urban social and transport geography is likely to be already imposing high relative travel costs on socioeconomically vulnerable outer-urban households. Under conditions where global demand for petrol outstrips supply resulting in on-going price rises, the capacity of Australian households to choose alternative means of travel will be a critical determinant of socioeconomic vulnerability.
It is worth noting the demand elasticities for public transport relative to fuel prices (DEPTP). The Australian Industry Commission (1993, pp. 44-46) suggested that the DEPTP was 0.07 , suggesting that a 1.0 per cent fuel price increase will produce a 0.07 per cent increase in public transport use. De Jong et al. (1998, p. 38) suggest that the long-run DEPTP is 0.26, while Taplin et al. (1999, p. 228) suggest that for Australia the DEPTP is 0.173 . The demand elasticity values suggest that only small shifts in public transport demand will occur as petrol prices risealthough these assessments are based on data collected during 'cheap oil' periods, with little expectation of high future fuel costs. However, historical demand elasticity figures may not be valid bases for assessments in circumstances where a long-term expectation of sustained fuel cost increases is apparent.

Some recent reports of changing demand are indicative. In Brisbane, public transport patronage grew by 14 per cent for July and August 2005 when compared with the same months in 2004 (Lucas 2005) while petrol prices increased 20 per cent over the same period (Figure 2). A recent AC Nielsen survey (AC Nielsen, 2006) found that 60 per cent of Australian households were making fewer car trips in response to increased fuel costs, while 19 per cent were using public transport more. The Commonwealth Bank research unit has reported an 8 per cent decline in Australian petrol consumption in 2005 , accompanied by a shift in consumption patterns, towards cheaper substitutes within product categories (COMMSEC, 2006).

Those with adequate access to high-quality public transport have the option of switching to this mode. However, public transport may not be a viable alternative for those who live in areas with poor access to public transport or with good access to infrequent or poorly connected services. There is a need for new research into the links between household socioeconomic wellbeing, transport access and travel costs. This study contributes to this task by assessing the relative vulnerability of three major Australian urban areas to the adverse socioeconomic impacts of increasing 
oil prices. We seek to understand how the socioeconomic impact of rising fuel costs will be distributed across Australia's highly differentiated urban geography. In particular, we wish to highlight those areas that stand to suffer most from the combined interaction of increased petrol prices, urban transport systems and social geography.

The important work of Newman et al. (1985) deserves revisiting here, given the detailed and painstaking methodologies these authors used to assess urban energy dependence and its implications for broader sociospatial differentiation. Newman et al. (1985) investigated household transport energy consumption for the city of Perth. Their approach used trip data from the 1976 Perth household travel survey to impute transport fuel consumption and assess the variation in consumption between urban locations comprising 38 zones compiled from postcode boundaries. Their results demonstrated clear locational differences in transport energy consumption. Inner urban zones exhibited lower transport energy consumption then either middle or outer zones, with the outer zones having highest transport energy use. By imputing a monetary cost of energy use, (Newman et al., 1985) were able to identify differences in travel costs between urban locations. The authors noted the important equity implications given the accelerating processes of sociospatial change that were forcing lower socioeconomic status households to outer areas of Perth. Further research by these authors (Newman et al., 1990) found similar results for Melbourne and Sydney at the 'local government area' (LGA) level.

Newman et al.'s $(1985,1990)$ methodology has substantial resonance for the present study. While they took secondary account of socioeconomic locational differences these earlier studies were primarily focused on urban spatial transport energy consumption. The spatial extent of the zones was quite large, while their original data are now 30 years old and may not reflect subsequent socio-spatial restructuring, subsequent urban development or new infrastructure provision. The study we describe in the remainder of this paper is partly informed by the Newman et al. analysis, but our ambition extends to comprehending the distribution of broader socioeconomic oil price impacts, rather than specifically on energy consumption. Because socioeconomic status is highly spatially differentiated at the local level in Australian cities (Gleeson and Randolph, 2001), we seek a highly detailed spatial resolution of 'oil vulnerability'. Our focus on socioeconomic status also takes into account not only oil vulnerability deriving from household transport patterns, but also implies an assessment of socioeconomic vulnerability to generalised price rises or adverse changes in social or economic conditions, such as an economic downturn, that might potentially derive from rising fuel costs. The methodology based on census data that we present is deployed easily across multiple urban jurisdictions and can be updated quickly as new census data becomes available.

\section{Assessing Australian Urban Oil Vulnerability: The VIPER}

There are insufficient data and few studies that can provide a comprehensive picture of the socioeconomic vulnerability of Australia's major cities to oil price rises. Because this line of inquiry is relatively novel, the authors are not aware of any directly comparable studies which can provide specific methodological guidance into the assessment of socioeconomic oil vulnerability at the household level. The methodology described below has thus been constructed from scratch. Our approach is set out in detail in anticipation that other scholars will extend, refine and enhance the techniques.

Our analytical approach is straightforward. To assess the potential exposure of households to adverse socioeconomic outcomes arising from increased fuel costs, we have created a basic locational measure of oil vulnerability that we term the "vulnerability index for petrol expense rises' (VIPER). The VIPER enables a spatial representation of oil vulnerability at the local suburban scale, thus providing an average relative 
vulnerability for urban areas that can enable interlocality comparisons at the metropolitan level.

VIPER is constructed from three variables obtained from the 2001 Australian Census that are combined to provide a composite vulnerability index that can be mapped at the geographical level of the Census Collection District (CD). ${ }^{2}$ The VIPER assesses the average vulnerability of the households within the $\mathrm{CD}$, rather than indicating the specific vulnerability of particular urban households. The census variables used are

- socioeconomic index for areas (SEIFA);

-household motor vehicle ownership; and

- car dependence for the journey to work (JTW).

The rationale for the selection, use and weighting of these variables deserves some justification. First, household socioeconomic status is a primary determinant of resilience or vulnerability to increased consumption costs, not only for transport fuel but also for goods and services whose prices are influenced by fuel costs. The Australian Bureau of Statistics (ABS, 2003) produces a Socio Economic Index for Areas (SEIFA) which is a composite measure that combines multiple household variables into a single figure to indicate household socioeconomic status. Higher socioeconomic status households, as indicated by high SEIFA scores, typically have higher incomes than lower SEIFA households. SEIFA takes into account multiple social and demographic variables, including but not restricted to household income. This multifaceted assessment includes other categories, such as occupational status, housing tenure and age. Our analysis assumes, however, that higher socioeconomic status households are more financially capable of absorbing increasing transport costs than lower socioeconomic status households and are therefore less vulnerable to petrol price rises. Because a household's capacity to meet rising fuel costs from its existing income is a key dimension of its resilience to oil price increases, socioeconomic status as measured by SEIFA is thus an important marker of oil vulnerability at the suburb level.

The second and third variables are used as indicators of household dependence on automobiles. The proportion of households with two or more motor vehicles is a basic indicator of demand for motor vehicle travel. The use of this variable as an indicator of oil vulnerability is based on the assumption that overall household motor vehicle ownership is related to the households' need for travel by automobile and that the greater the level of vehicle ownership for a given household, the higher that household's dependence on oil. Similarly, the use of motor vehicles for work journeys serves as an indicator of the dependence on motor vehicles for urban travel of those households, and thus also indicates exposure to oil price rises. The journeyto-work mode as revealed by census data is not an ideal indicator of travel preference, relative to other data sources such as household travel surveys. The Census JTW mode share for car travel tends to be lower than the share of all trips taken by car. However, given that census data provide both socioeconomic and transport data and are easily combined, the use of car ownership and journey-to-work variables as automobiledependence indicators remains valid within the context of VIPER.

Because VIPER is a composite index, a weighting was used to combine the three variables. First, each variable was sorted into relative value categories based on the 10th, 25 th, 50th, 75th and 90th percentiles for each city. Census districts were assigned values of 5 to 0 depending on which percentile they were situated within. These rankings are set out in Table 4.

The final VIPER value for any $\mathrm{CD}$ reflects the sum of these variable rankings. Hence a CD within the 10th percentile for SEIFA, 50th percentile for car ownership and 75th percentile for JTW by private motor vehicle would receive a value of $5+3+4$, or 12 . However, our assessment is that the three variables we have selected are not of equal importance in determining household vulnerability. Thus VIPER has been split into two 
Table 4. Value assignment relative to census district percentile for VIPER variables

\begin{tabular}{lccc}
\hline & \multicolumn{3}{c}{ Value assigned } \\
\cline { 2 - 4 } Percentile & SEIFA & Car own $\geq 2$ & JTW by car \\
\hline 100 & 0 & 5 & 5 \\
90 & 1 & 4 & 4 \\
75 & 2 & 3 & 3 \\
50 & 3 & 2 & 2 \\
25 & 4 & 1 & 1 \\
10 & 5 & 0 & 0 \\
\hline
\end{tabular}

equal-weight indicator variable sets, of which the first comprises SEIFA, while the second comprises car ownership and JTW. This is achieved by doubling the index value for SEIFA, thus creating a 20-point scale. The variable weightings for VIPER are displayed in Table 5. We note that these weightings are based on a simple balancing of SEIFA and automobile use variables. We are unaware of any research that provides insight into a better weighting that could be used for assessing oil vulnerability, using Australian Census data.

A CD that scored the worst possible rating for each of the 3 variable counts would receive 20 points, while the best would receive zero. These scores provide a range of values that can be grouped and mapped for each $\mathrm{CD}$ for Australian metropolitan areas. Selection of CDs was based on the ABS definitions of urban centres. Maps were shaded to distribute oil vulnerability scores using equal ranges.

\section{Results of the Analysis}

The results of the oil vulnerability mapping for Brisbane, Sydney and Melbourne are presented in Figures 3-5. Each city displays clear spatial patterns that indicate a highly uneven distribution of potential vulnerability to oil price rises. The following section discusses each of these cities in turn.

\section{Brisbane}

Brisbane comprises a large core area from which four corridors of development extend north, west, south and east. The VIPER results for Brisbane demonstrate a wide variation in oil vulnerability levels between the city's localities (Figure 3). The central area has a relatively low vulnerability rating with most CDs in this area scoring lower than 7 on the VIPER. Areas immediately to the north and west and south-east of the central area fared less well. The most vulnerable suburbs, according to our analysis, are generally concentrated along Brisbane's outer development corridors. Thus, for example, the area towards Ipswich in the south-west, Beenleigh in the south-east and Caboolture in the north all contain localities that appear to be highly vulnerable. Of these, the southeastern corridor displays the most concentrated vulnerability. The south-western corridor also contains highly vulnerable areas although these are less concentrated than in the south-east. The eastern corridor contains only a few areas of high vulnerability but does include a number of modest-vulnerability areas. The north also has a mix of ranges, although moderate and high-vulnerability areas predominate.

The areas of highest vulnerability are very similar to localities that typically appear in measures of socioeconomic disadvantage, such as Logan, Beenleigh and the Ipswich corridor. This is not surprising given that half of VIPER is based on the SEIFA index. However, travel behaviour patterns do not

Table 5. Variable weighting for VIPER

\begin{tabular}{lccc}
\hline Indicator & SEIFA & $\begin{array}{c}\text { Proportion of households } \\
\text { with } \geq 2 \text { cars }\end{array}$ & $\begin{array}{c}\text { Proportion of work trips } \\
\text { by private motor vehicle }\end{array}$ \\
\hline Potential points & 10 & 5 & 5 \\
Weighting (percentage) & 50 & 25 & 25 \\
\hline
\end{tabular}




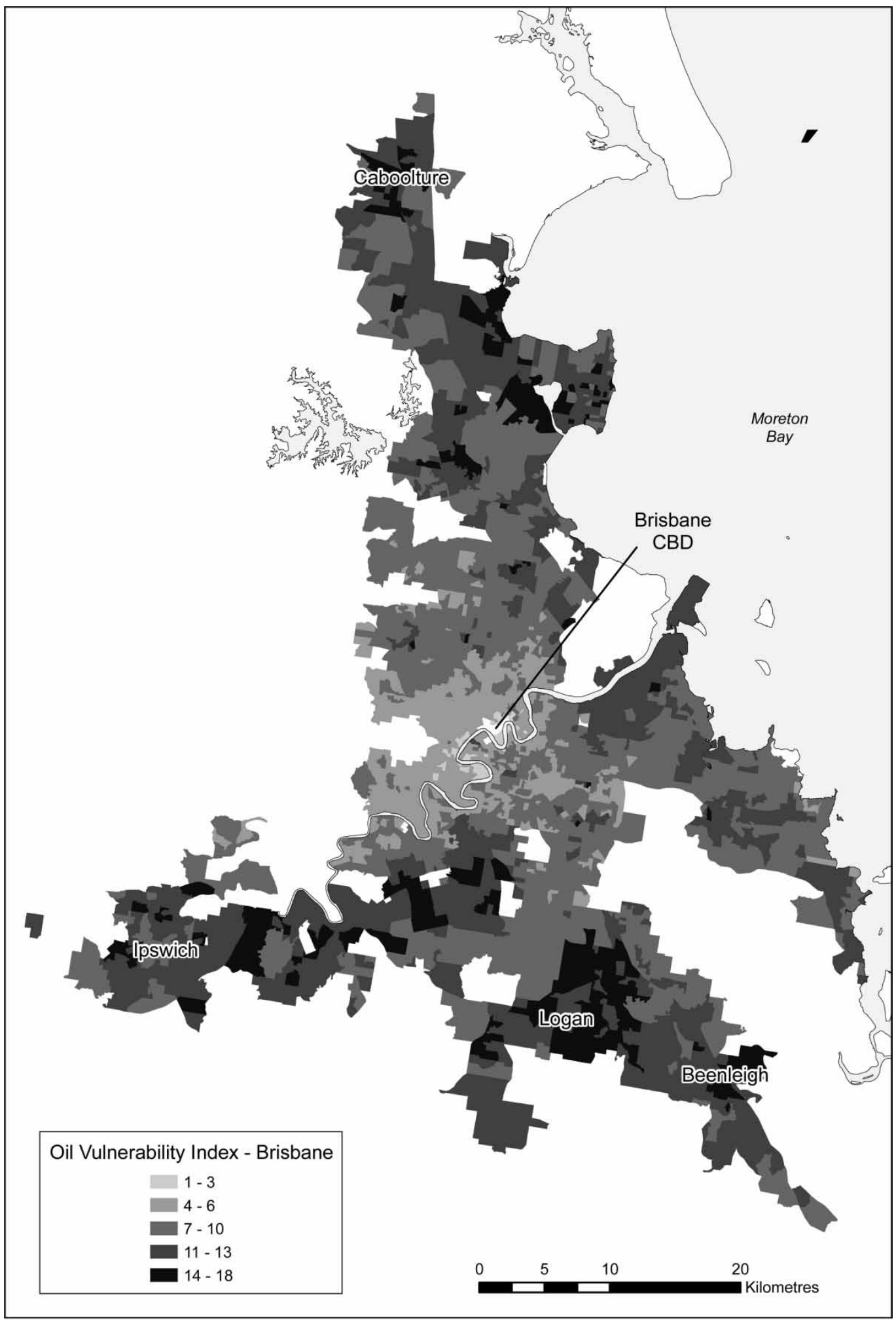

Figure 3. Oil vulnerability in Brisbane. 


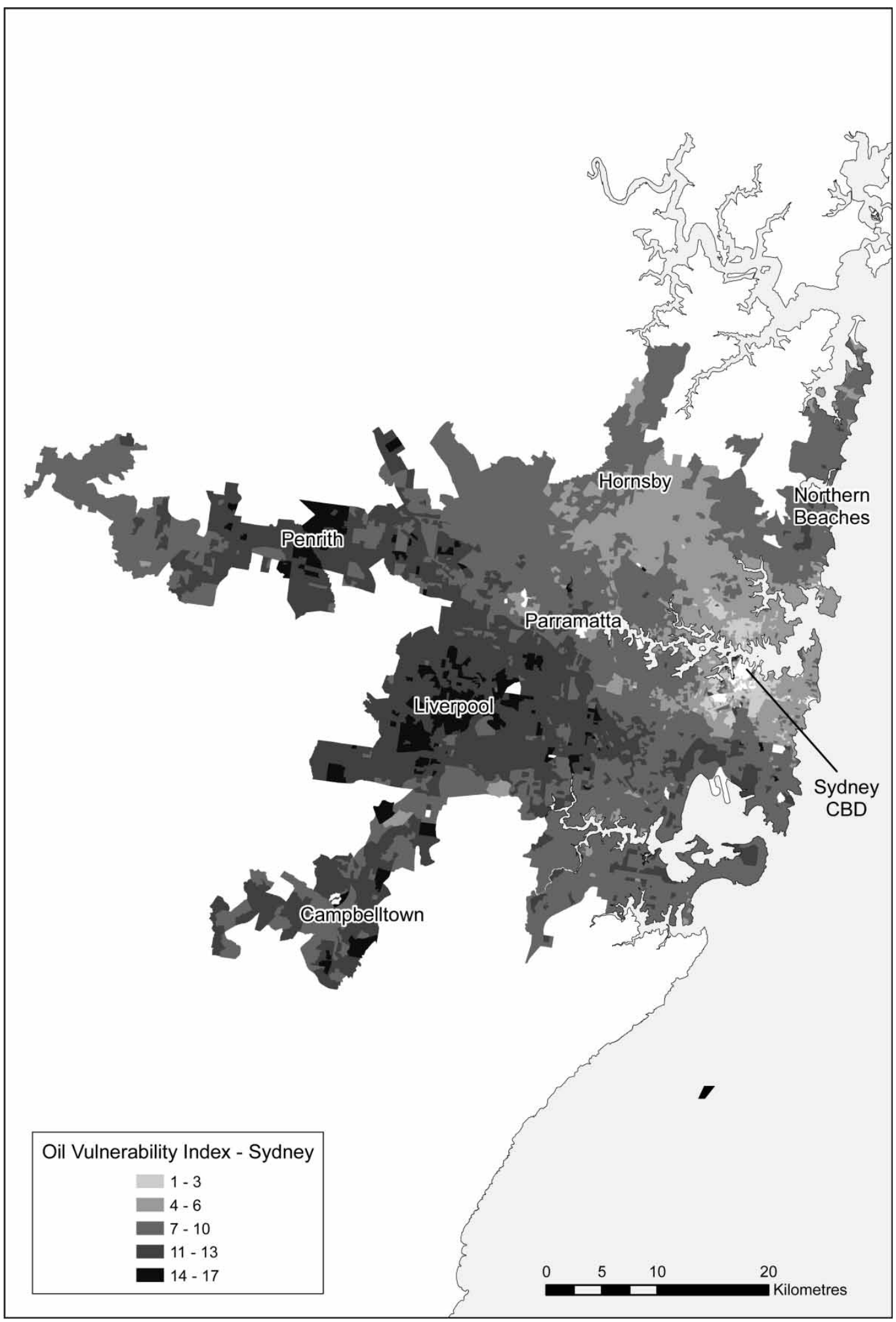

Figure 4. Oil vulnerability in Sydney. 


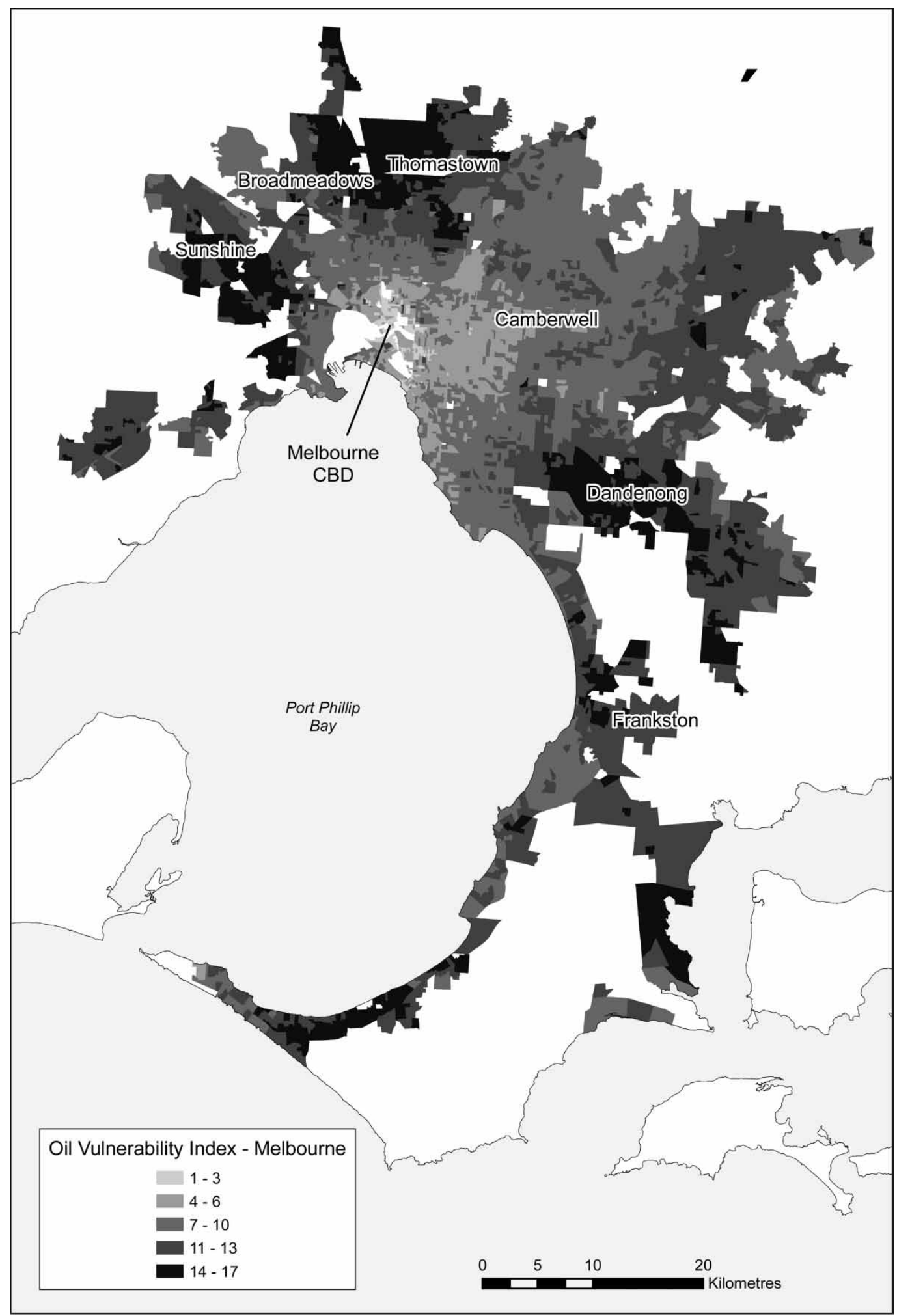

Figure 5. Oil vulnerability in Melbourne. 
appear to be diminishing the distribution of socioeconomic disadvantage. Indeed, low socioeconomic status appears to be exacerbated by automobile dependence within the Brisbane metropolitan area.

The distribution of public transport services is not directly depicted in our study, but it suffices to observe that the higher VIPER ratings obtain in outer areas where public transport is of lower quality relative to inner and central locations. While many of the growth corridors contain rail services, the integration of these with other modes is typically underdeveloped, as is the case in the other two cities we examined.

\section{Sydney}

Sydney's urban area surrounds Sydney Harbour, with development to the north and south extending west and then dividing into two growth corridors to the north-west and south-west. As is the case for Brisbane, Sydney is strongly patterned in terms of oil vulnerability, as revealed by our analysis (Figure 4). The broad area of northern Sydney from the northern beaches to the Parramatta River displays low to moderate socioeconomic vulnerability to increased oil prices, particularly the CBD-Hornsby corridor. A narrower band from the southern harbour mouth to Parramatta also displays low oil vulnerability, particularly within and to the immediate east of the CBD.

High oil vulnerability is concentrated in Sydney's west, particularly in a broad area of localities south-west of Parramatta which extends along both the north-west and southwest corridors. Of particular note are the areas surrounding Liverpool which contain a large cluster of highly vulnerable localities. Similar, although not as extensive, concentrations of vulnerability are found in the Penrith and Campbelltown urban corridors to the north-west and south-west resepctively.

The geography of oil vulnerability in Sydney is clearly marked and in part reflects existing socio-spatial divisions, such as those reported by Baum et al. (2005). The most vulnerable areas are situated in Sydney's western suburbs, while the least vulnerable areas are in the northern and eastern suburbs, a geographical divide that has long been scholarly and popularly appreciated. But the quality of public transport service is also spatially differentiated in Sydney. Mees (2000b) has observed that services in the west are typically of lower quality than in Sydney's east, while VKTs are higher in the west than the east. These patterns are reflected in the VIPER results suggesting that public transport is playing a critical role in oil vulnerability. The divergences in combined socioeconomic status and car dependence suggest that rising oil prices would have different socio-spatial impacts across Sydney. It is worth noting the large number of areas with VIPER index ratings of 7-11 (see later discussion). These areas are moderately vulnerable to oil price rises and are mostly situated in the northern suburbs and in large areas of the south. Only the most central and eastern localities have relatively low vulnerability, although lower ratings are apparent along the rail line through central northern Sydney.

\section{Melbourne}

The VIPER results in Melbourne also display strong geographical differentiation, similar to that found in Brisbane and Sydney (Figure 5). The areas with the lowest vulnerability ratings are largely situated in close proximity to the Melbourne CBD, particularly the inner eastern suburbs. Lower vulnerability areas are also found in Melbourne's inner north and particularly within the inner east, such as the localities surrounding Camberwell. Beyond these areas is a ring of moderate vulnerability localities, around 25 kilometres from the $\mathrm{CBD}$ in the east and 15 kilometres in the north.

The most vulnerable localities in Melbourne are those located on the urban fringe and within the ageing industrial areas, such as Sunshine and Altona in the west, Broadmeadows and Thomastown in the north, as well as Dandenong and Frankston in the south-east. These areas contain large concentrations of Melbourne's most vulnerable 
localities and are larger in area than most of those found in either Sydney or Brisbane. Clearly, Melbourne's lower socioeconomic status households in fringe areas face considerable challenges from escalating fuel costs.

While socioeconomic status is clearly associated with oil vulnerability in Melbourne, the transport geography is also playing a role. Many authors have described the poor quality of outer-suburban public transport services in Melbourne (Mees 2000a; Morris et al., 2002). While our study has not taken public transport provision directly into account, it is apparent from this background understanding and from the JTW mode component of VIPER, that inadequate public transport is implicated in high outer-suburban oil vulnerability for Melbourne.

\section{Population Distribution of Oil Vulnerability}

This study has focused primarily on the locational aspects of oil vulnerability. The analyses we have presented focus on mapping the spatial distribution of oil vulnerability. Such maps provide no indication of the actual population affected by this problem. Therefore, we have enumerated the number of persons within each of the oil vulnerability categories for Brisbane, Sydney and Melbourne (Figures 6-8). These figures assist to provide greater appreciation of the scale of potential impact in terms of the numbers of people who will be affected by oil vulnerability and increased fuel costs. Unfortunately, these figures cannot be used for intercity comparisons because VIPER measures relative, not absolute, oil vulnerability. This means that it can be used for comparative assessments of localities within, but not between, cities. However, the general shape of the distributions portrayed in these charts is indicative of vulnerability within a given city such that a distribution that is skewed to the right (such as Melbourne) indicates a probable greater extent of vulnerability than a distribution skewed to the left (such as Brisbane or Sydney).

\section{Brisbane}

Brisbane's total population of 1500000 displays a 'normal' distribution of oil vulnerability with relatively few households at low or high risk, and a large number in the moderate vulnerability categories (Figure 6). This distribution is skewed slightly towards moderate vulnerability levels with approximately 955000 or just under 64 per cent of Brisbane's population situated in localities that had a VIPER rating between 4 and 10. Just over 23000 persons were in the lowest vulnerability range of $1-3$ (approximately 2 per cent), while approximately 522000 persons rated in the moderate or high VIPER categories of 11-18 (approximately 35 per cent

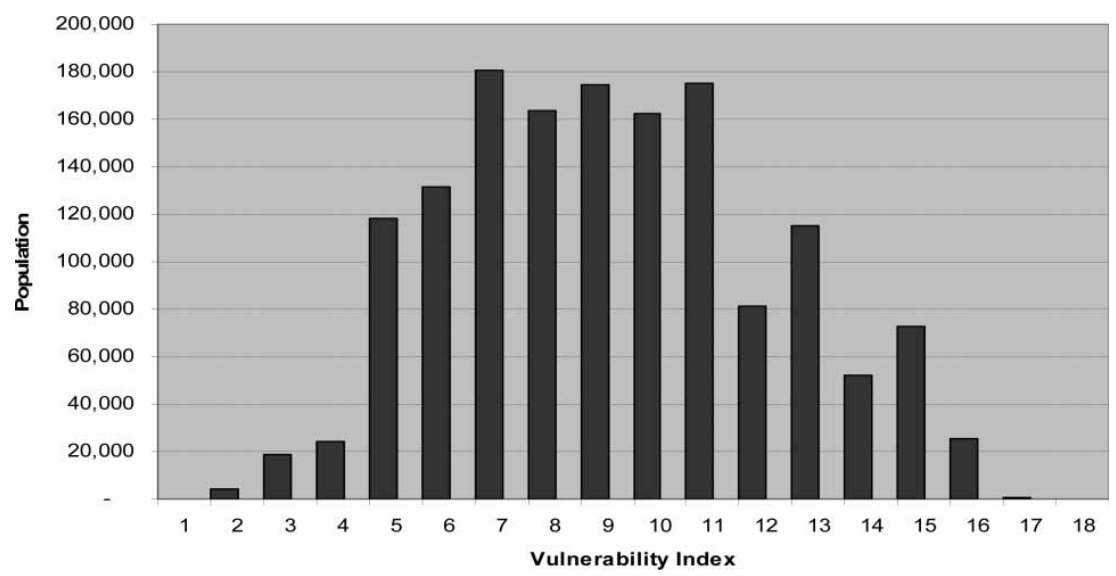

Figure 6. Distribution of oil vulnerability for total population of Brisbane. 


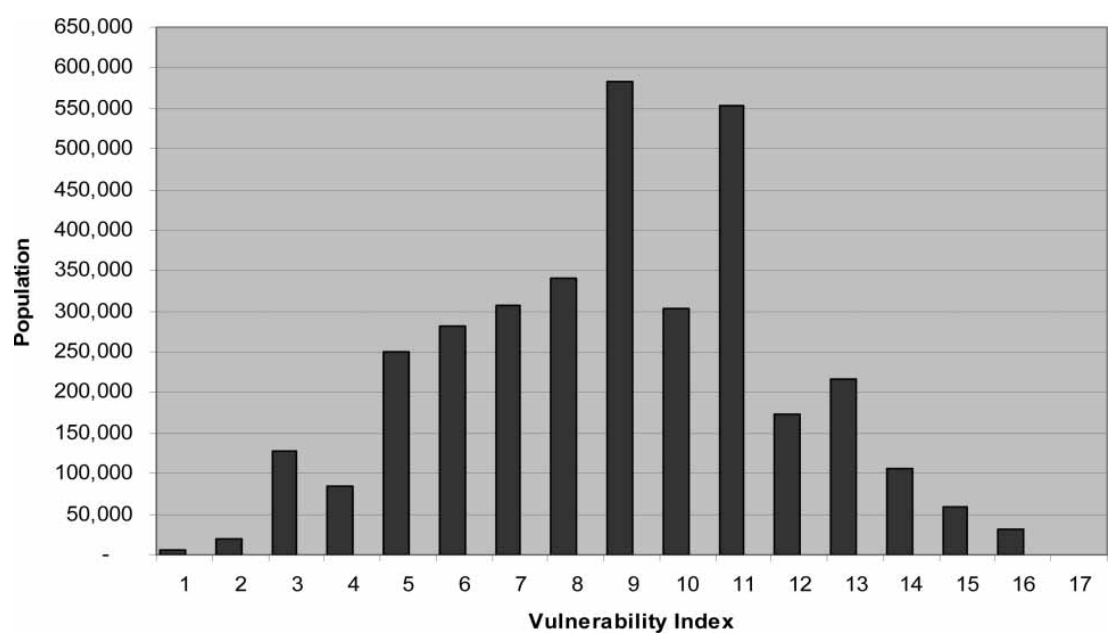

Figure 7. Distribution of oil vulnerability for total population of Sydney.

of the population). Just over 150000 (10 per cent) of Brisbane's population were situated in the highest VIPER categories of 14-18. Clearly, a substantial proportion of Brisbane's population is at moderate or high risk of socioeconomic impacts arising from high or increasing fuel prices. As Figure 5 demonstrated, the majority of this population is situated in outer-suburban locations.

\section{Sydney}

In Sydney, the primary observation is the relative increase in population between Sydney and Brisbane and Melbourne. Sydney's population is more than double that of Brisbane. Again, however, most of Sydney's population is situated within the moderate vulnerability localities under VIPER (Figure 7). Approximately 2.15 million people (62 per cent) live in VIPER categories 4-10, with 584000 (17 per cent) in category 9. Those within the least vulnerable VIPER categories of 1-3 numbered slightly less than 153000 (approximately 4.4 per cent). Just over 1.14 million (or 33 per cent) were rated 11 or higher, suggesting that a large number of people will be adversely or very adversely

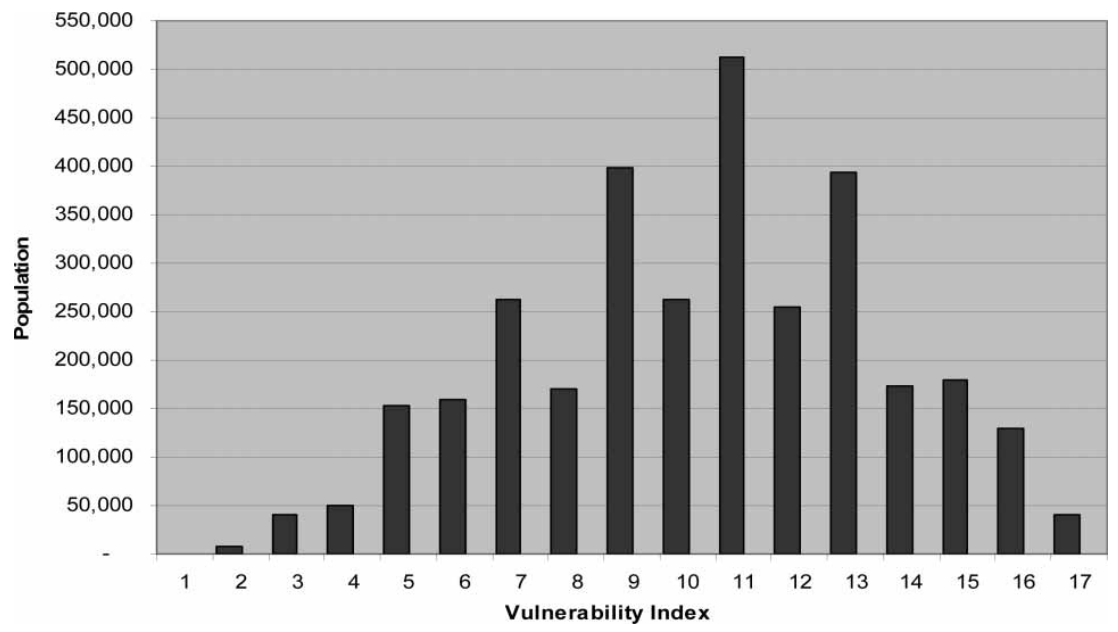

Figure 8. Distribution of oil vulnerability for total population of Melbourne. 
socioeconomically impacted by high or rising fuel costs. As in the cases of Brisbane and Melbourne, the majority of this population is situated in the outer suburbs of Sydney, particularly in the outer north-west and south-west.

\section{Melbourne}

The pattern of distribution of relative oil vulnerability within Melbourne's population appears broadly similar to the patterns found in Brisbane and Sydney, albeit with some important differences (Figure 8). In Melbourne, approximately 46 per cent of the population (1.46 million people) are situated within localities that are rated at moderate vulnerability (categories 4-10) to oil prices increases on VIPER. While these are relative measures and thus not suitable for intercity comparisons, a higher proportion of Melbourne's population falls within the higher VIPER categories when compared with Sydney or Brisbane. Thus slightly fewer than 53 per cent of Melbourne's population (1.82 million people) are in localities that received a VIPER oil vulnerability rating of 11 or higher. Just under 350000 (11 per cent) of Melbourne's population are in very high vulnerability localities, according to VIPER. By comparison, only 1.5 per cent (fewer than 49000 persons) of Melbourne's population are situated in low oil vulnerability localities. Melbourne's VIPER ratings are clearly skewed towards higher relative vulnerabilities than is the case with Brisbane or Sydney.

\section{Indicative Household VIPER Differences}

VIPER relies on basic ABS census data and half of the index weight derives from the SEIFA socioeconomic rating. There is a risk therefore that VIPER merely replicates the distribution of socioeconomic status within Australian cities rather than genuinely revealing patterns of oil vulnerability. We considered it useful to assess briefly how some other census variables were distributed within the high and low oil vulnerability locations, to assess whether this concern is warranted (Table 6). The patterns illustrated by these data, and the implications they suggest, merit discussion.

The proportion of detached dwellings provides a gross indicator of the relative residential density of localities and is not directly related to the VIPER variables. Detached dwellings formed a very low proportion of the housing stock within the low VIPER areas for all three cities, but comprised a high proportion of the housing stock within high vulnerability VIPER areas. In Sydney, the average proportion of detached dwellings within low VIPER areas was less than 5 per cent, which contrasts markedly with the proportions for all of Sydney (57.8 per cent) and for high VIPER Sydney localities (71.5 per cent). Comparable patterns were found in Brisbane and Melbourne suggesting that detached dwellings are associated with higher oil vulnerability in all three cities. This is a potentially contentious observation given the intensity of debates over urban consolidation policy in Australia. While our

Table 6. Selected household and dwelling characteristics per low and high VIPER categories

\begin{tabular}{|c|c|c|c|c|c|c|c|c|c|}
\hline \multirow[b]{2}{*}{ Household characteristic } & \multicolumn{3}{|c|}{ Brisbane } & \multicolumn{3}{|c|}{ Sydney } & \multicolumn{3}{|c|}{ Melbourne } \\
\hline & All & Low & High & All & Low & High & All & Low & High \\
\hline Detached house & 75.1 & 13.0 & 78.8 & 57.8 & 4.9 & 71.5 & 67.2 & 5.9 & 76.9 \\
\hline Owner-occupied dwelling & 63.3 & 28.3 & 49.6 & 62.2 & 37.1 & 46.3 & 68.9 & 29.7 & 68.2 \\
\hline $\begin{array}{l}\text { Professional or administrative } \\
\text { occupation }\end{array}$ & 37.6 & 59.0 & 17.0 & 42.2 & 64.3 & 17.5 & 41.1 & 63.8 & 20.0 \\
\hline Income $\leq \$ 400$ & 19.5 & 24.1 & 29.6 & 16.1 & 12.5 & 29.6 & 18.5 & 18.8 & 25.8 \\
\hline Income $\geq \$ 1500$ & 18.5 & 20.3 & 5.8 & 28.6 & 38.7 & 9.4 & 22.2 & 29.8 & 9.6 \\
\hline Number of CDs & 2628 & 42 & 265 & 5581 & 343 & 293 & 5457 & 105 & 819 \\
\hline
\end{tabular}


results should not be considered definitive, they clearly indicate that more research and analysis into this issue are required.

Owner-occupation appears to be associated with higher oil vulnerability, for all three cities. The effect is stronger in Melbourne, where the average proportion of owneroccupier households in high oil vulnerability localities was almost double that for low oil vulnerability areas. This effect was apparent but moderate in Brisbane and much weaker in Sydney. If SEIFA was determining the distribution of oil vulnerability, we would expect to see lower levels of owner-occupation in the high vulnerability areas, on the assumption that lower socioeconomic status households are less likely to be present in this tenure (Winter and Stone, 1998), but this is not the case. An explanation might be that owneroccupiers have higher rates of car dependence. This seems plausible given that owneroccupation is higher in middle and outer localities, while rental households are more predominent in inner locations where multiunit dwellings are more prevalent and where public transport services are better. Tenurial differences in oil vulnerability are therefore perhaps more due to urban structural factors than to socioeconomic factors.

The SEIFA effect is apparent in the divergent spatial distribution of professional occupations relative to oil vulnerability. Professionals are resident in much higher proportions in low oil vulnerability areas than in high oil vulnerability areas for all three cities. This effect perhaps reflects Australian urban geographyprofessionals are predominantly located within central and inner-city locations (O'Connor and Healy, 2002). But these are also the areas where public transport services are of highest quality and where private motor vehicle travel is less compulsory relative to middle and outer areas. This pattern suggests that VIPER is operating as a composite index that reflects an interaction between the geography of SEIFA and transport patterns and is not heavily biased towards one element.

The income variables only partly reflect the SEIFA elements of the VIPER index. The proportion of low-income households was relatively lower in the low oil vulnerability areas than in the high oil vulnerability areas, for all cities. These differences were strongest in Sydney but were slightly weaker in Melbourne and much weaker in Brisbane. By contrast, the proportion of households on high incomes was at least three times greater in low oil vulnerability areas than in high oil vulnerability areas. High income appears more strongly associated with low oil vulnerability than low income is with high oil vulnerability suggesting that a low SEIFA score does not necessarily result in higher oil vulnerability. While this finding may partly reflect spatial SEIFA patterns, in particular the inner-city concentration of high-incomegroups, it is also associated with the higher availability of high-quality public transport services in inner locations. As other authors have suggested (Morris et al., 2002; Cheal, 2003) wealthier households have been able to capture locations with high-quality public transport services and this is subsequently putting these groups at lower socioeconomic risk from rising fuel prices.

The variables we have considered above indicate that the relationship between socioeconomic status and oil vulnerability is more nuanced than may have been suggested by the weighting of the SEIFA values in the VIPER index. While some household characteristics, such as the proportion of professionals or income level, appear to be linked to locational SEIFA values, the transport factors within VIPER are also exerting an important influence on oil vulnerability. The results for dwelling structure suggest that urban density, and thus broader urban structure, is playing a critical role. These results also suggest that there is much further investigation needed to draw out the links between socioeconomic status, oil vulnerability and urban geography in Australia.

\section{Discussion}

This paper began with a discussion about the socioeconomic differentiation of Australian cities and the potential interaction and impact of these patterns with higher fuel prices. 
The analysis we have presented suggests that the socioeconomic impacts of rising fuel costs are likely to be unevenly distributed across Australian cities and across the populations of these cities. In Brisbane, Sydney and Melbourne, it is generally those households that are located in socioeconomically disadvantaged and car-dependent outer-suburban locations that will be most vulnerable to current high and potential future rising petrol prices. By comparison, those localities in central and inner areas will be relatively less socioeconomically disadvantaged as a result of rising fuel prices given the location of employment particularly for highwage sectors, which is concentrated in the CBD of most Australian cities.

The cities we have examined display a high level of local VIPER differentiation, particularly among some of the outer metropolitan corridors. The Caboolture corridor in northern Brisbane and the Campbelltown corridor in outer south-west Sydney appear highly variegated in terms of the VIPER rating, although generally these tend towards the more vulnerable categories of the spectrum.

Rising fuel costs are likely to fall more greatly on lower socioeconomic suburban groups in outer suburban areas for two main reasons. First, socioeconomic vulnerability already places these households at greater risk of adverse impacts from any economic change, such as industrial restructuring, rising interest rates, increasing unemployment or workplace deregulation. Secondly, however, the specifically greater dependence on automobiles for urban travel is the critical factor that places these households at much greater risk from rising fuel prices. Australian urban scholars have for many years warned of the problems associated with high levels of car dependence in Australian suburbs, particularly those developed after World War II (Neutze, 1977; Morris, 1981; Manning, 1984; Newman and Kenworthy, 1999; Mees, 2000a). Car dependence in these areas makes the residents highly vulnerable to increased fuel costs, particularly because they rely on cheap petrol to access employment and services. This impact is compounded by the lack of alternative modes, such as public transport, walking and cycling, and by the wide dispersion of employment and services that necessitates long, often circumferential, journeys.

Our results may be in part an artefact of the weighting used in our index, but the VIPER results imply that low socioeconomic status and high car dependence are strongly co-located in Australian cities. While higher socioeconomic status groups may be equally car-dependent, this is moderated by their higher incomes. Additional inspection of non-VIPER household characteristics (Table 6) suggests that more nuanced relationships are at work, particularly regarding dwelling type and tenure. There is a need to understand better these dynamics at the household level to assess more fully the relationship between car dependence, socioeconomic status and urban structure.

\section{Opportunities for Further Study}

The idea of socioeconomic oil vulnerability remains largely unexplored in social science. Given the relative novelty of this concept, there is much scope for further investigation and development of the issue and the methods of analysis. It is worth reflecting on the opportunities for further research that this paper suggests. First, our methodology measures imputed oil vulnerability. That is, we assume that combining socioeconomic and automobile use variables does provide insight into the likely distribution of socioeconomic impact from oil price rises. Given that there is little existing research to support this assumption, this assumption seems justified and is sufficiently robust to provide strong insight at the exploratory level. The use of census data makes our methodology for assessing of oil vulnerability easily replicable for other jurisdictions. We hope that others will replicate and extend our analysis.

Secondly, the selection of variables is limited to three census statistics based on a presumed relationship between these variables. However, we consider that the weighting of socioeconomic and travel variables is justified by the scholarly literature on this topic area which we discussed earlier. In favour of our 
methodology, there are effectively no alternative datasets that can respond to the questions we pose, at a spatial scale finer than the suburb level. Only census data provide comprehensive information on household disadvantage and basic travel characteristics with a sample size that allows detailed mapping at the scale of the local CD.

A more sophisticated analysis of suburban oil vulnerability could be undertaken if a better dataset was available that could reveal information about household socioeconomic status, vehicle and travel costs, and the access to and use of different travel modes, as well as the relative weighting of socioeconomic and transport mode factors-and which collated data for all Australia's major cities. As no such dataset exists in Australia, some confection and imputation of variables is likely to be inevitable. The approach we have presented here is therefore the best available measure of the spatial distribution of socioeconomic oil vulnerability in Australian cities. Given the importance of the topic, we hope that our approach will stimulate international scholarly debate about methodologies for investigating this crucial issue. Although it was different in specific focus from that of our study, a revisiting of the earlier Newman et al. work on energy consumption may offer further fruitful points of departure in this area of analysis.

Our analysis has not attempted to assess the potential for modal switching between automobiles and public transport in the cities we have assessed. Australian literature suggests that locations where high-quality public transport is provided will exhibit higher proportions of trips for this mode (Mees, 2000a; Morris et al., 2002) such that existing locational patterns of car dependence reflect the current availability of public transport in those areas. It would, however, be feasible to model potential public transport accessibility, as did Buchanan et al. (2005) and $\mathrm{Wu}$ and Hine (2003).

The temporal dimension of public transport services, in terms of service frequency and periods of operation (Dodson et al., 2004), is critical in the evaluation of adequacy of public transport access, as temporal factors can dramatically impact on the assessment of public transport quality. Research of this sort requires intensive use of analytical resources, even for just a single city (Buchanan et al., 2005). Adequate data to undertake such comprehensive spatial and temporal access assessments, particularly interjurisdictional comparative evaluations, are not readily available. Our approach is thus the simplest, spatially most comprehensive and detailed, and most methodologically efficient assessment of oil vulnerability presently available in Australia.

We reiterate that our index is a measure of potential vulnerability. This means that, while we identify which households are likely to be most affected by rising fuel costs, we cannot definitively conclude how rising oil prices will impact on local areas or what the response may be at the local household or neighbourhood level in terms of travel mode shifts or changing consumption patterns. The uncertainty over the future cost of fuel is matched by uncertainty about the nature of household response. However, on the balance of socioeconomic resilience we anticipate that our assessment provides a strong and clear insight into the likely distribution of oil price rise impacts across the suburban social geography of the cities we have analysed.

Finally, the relevance of our study within an international context deserves some comment. We note that the socio-spatial structure of Australian cities differs from many overseas jurisdictions, particularly those in North America and Europe, including the UK. With some exceptions, modest and lower socioeconomic status households are generally located in the outer suburbs of Australian cities. Socioeconomic oil vulnerability may not be as great for lower socioeconomic households in European or some North American cities as it appears to be for those in Australian cities, given different socio-spatial and transport geographies. Differing levels of energy consumption between cities will, however, also have some bearing on this issue (Table 2). Nevertheless, application of our basic assessment approach may assist to illuminate these critical differences and the myriad dynamics that underpin them. 


\section{Conclusions and Policy Directions}

Most commentators anticipate that oil prices will remain high for the foreseeable future and may continue to rise over time. It is critical that scholars and governments attend to the way in which these impacts will be distributed across Australia's cities. Clearly, outersuburban areas, locations that contain low socioeconomic status populations and suburbs which have high levels of car dependence will be the most affected by such increases. There is potential for rising fuel costs to generate new forms of urban social differentiation, segregation or exclusion that are linked to transport infrastructure and services, but presently we have insufficient understanding to contemplate accurately what the contours of these new patterns may be. Acknowledging the potentially highly uneven and multidimensional distribution of the impacts from urban fuel prices rises will be critical to policies that governments may pursue to adjust our urban systems to cope with costlier fuel.

Australian urban transport infrastructure priorities remain focused on building roads for automobiles. The analysis we have undertaken suggests a reconsideration of these priorities given the potential impact of rising fuel prices and or the arrival of a peak oil scenario. At a minimum, public decisions regarding transport investment should enunciate how oil prices have been factored into the feasibility analyses and what strategies will be employed to ameliorate their impact. Local suburban infrastructure such as feeder bus services to rail networks may provide better longer-term investments than major roads.

The interpretation of our oil vulnerability results is partly speculative, but the data they deploy are comprehensive and solid. There is a critical need, however, for more research into the question of the household response to increasing oil prices, including the elasticity of demand for alternative modes and potential changes in the composition of household spending. Development of a measure of household 'transport stress' is a critical research priority. Given that our analysis suggests there will be important spatial differences in household vulnerability to higher oil prices, suppliers of goods and services may wish to assess their spatial position in Australia's urban markets. Suppliers of public transport services need to begin assessing likely areas of new demand, while those with a stake in the consumer retail sector may wish to note those areas that may experience reduced demand for consumer items.

Few studies in recent years have attempted to assess oil vulnerability at the local spatial scale, within Anglophone scholarship. In part, the purpose of our study is to invite and encourage the engagement from colleagues regarding the relevance of oil vulnerability as a concept, the methods to define and assess this phenomenon and the policy responses that are necessary. We hope that this paper will assist the stimulation of this area of research within the international urban research community.

Speculating whether excess demand or some 'peak oil' scenario will generate increases in the short- or medium-term costs of motor vehicle travel is as risky an enterprise as the bets waged by international oil futures traders hoping to second-guess geology. But the future lasts a long time and adjusting to a future of uneasy oil may not be rapidly achieved. Even if energy markets were able to adjust quickly to much higher oil prices, our production and distribution systems are unlikely to be so responsive. The capacity for urban households to respond to such market signals is likely to be highly geographically differentiated. Assessing present options and adjusting urban priorities now may avoid much greater problems in the future.

\section{Notes}

1. Analogue organisation to the UK or US Automobile Associations.

2. Collectors Districts are smaller in area than suburbs and typically contain approximately 200 households. CDs are larger than the mesh block units used in US, Canadian and UK censuses. 


\section{References}

AA Motoring Trust (2005) Four-pence drop in petrol price takes time to work through to pumps, 21 September (http://www.aatrust.com/ index.asp?Page ID $=31 \&$ Year $=2005 \&$ NewsID $=$ 56; accessed 6 January, 2006).

abS (Australian Bureau of Statistics) (2001) Statistical Geography Volume 3 Australian Standard Geographical Classification (ASGC) Urban Centres/Localities. Cat. No. 2909.9. Canberra: Australian Bureau of Statistics.

ABS (2003) Information Paper: Census of Population and Housing-Socio-Economic Indexes for Areas. Cat. No. 2039.0. Canberra: Australian Bureau of Statistics.

ABS (2005a) Consumer Price Index June Quarter. Cat.No. 6401.1. Canberra: Australian Government.

ABS (2005b) Consumer Price Index September Quarter. Cat. No. 6401.0. Canberra: Australian Government.

ACCC (Australian Competition and ConsuMER COMMISSION) (2005) Snapshot of Australian petrol prices. Media release, Canberra, 30 September.

AC NIELSEN (2005) High petrol prices start to bite into out-of-home dining budgets (http://au. acnielsen.com/news/documents/Petrolpriceand consumptionrelease.pdf; accessed 13 December, 2005).

AC NIELSEN (2006) Fuel price survey: results for Australia. AC Nielsen, Sydney (http://au. acnielsen.com/news/documents/AusPROmniFuelresults.pdf; accessed 11 April 2006).

BAKER, J. (2005) Watchdog should monitor petrol prices: NRMA, Sydney Morning Herald, 22 September.

Baum, S., O'Connor, K. ET AL. (2005) Faultlines Exposed: Advantage and Disadvantage across Australia's Settlement System. Melbourne: Monash University Press.

BRAMmALl, B. (2005) Escalating fuel prices chomp into Maccas, Courier-Mail, 17 September, p. 37.

Buchanan, N., Evans, R. and Dodson, J. (2005) Transport disadvantage and social status: a Gold Coast pilot study. Research Monograph No. 8, Urban Research Program, Griffith University, Brisbane.

Burnley, I., Murphy, P. et AL. (1997) Selecting suburbia: residential relocation to outer Sydney, Urban Studies, 34(7), pp. 1109-1127.

CABle, V. (2005) We have been here before: the price of oil will fall, The Guardian Unlimited, 8 August.

CAmpbell, C. (2003) The peak of oil: a geological and political turning point for the world, in: N. Low and B. GleEson (Eds) Making Urban
Transport Sustainable, pp. 42-66. Basingstoke: Palgrave Macmillan.

Campbell, C. (2005) Oil Crisis. London: Multiscience Publishing.

Cheal, C. (2003) Transit rich or transit poor: is public transport policy in Melbourne exacerbating social disadvantage? Hons. thesis, University of Melbourne.

COMMSEC (2006) Petrol prices: learning to live with a higher level of pain. Economic Issues Series, Commonwealth Bank, Sydney (http:// www.research.comsec.com.au/ResearchFiles/ $\mathrm{P} /$ Petrol\%20pain\%20Mar06.pdf; accessed 11 April 2006).

DefFeyes, K. (2001) Hubbert's Peak: The Impending World Oil Shortage. Princeton, NJ: Princeton University Press.

Deffeyes, K. and Huber, P. (2005) The end of oil-oil is here to stay, Time Magazine, 13 October (http://www.time.com/time/magazine/ printout/0,8816,1122019,00.html).

DIPNR (DEPARTMENT OF INFRASTRUCTURE, Planning and Natural Resources) (2003) Regional transport indicators for Sydney. Transport and Population Data Centre, NSW Government, Sydney.

DIPNR (2005) Car travel in Sydney: changes in the last decade. DIPNR, Sydney.

Dodson, J. (2003) Visions for 2030: housing and transport planning in Labor's Metropolitan strategy, in: D. HAYWARD and P. Ewer (Eds) Visions for Victoria: Proposals to Achieve Public Sector Renewal in Australia, pp. 191210. Melbourne: Vulgar Press.

DoDson, J. (2004) Is there a spatial mismatch between housing affordability and employment opportunity in Melbourne? Paper presented at the Natonal Conference on the State of Australian Cities, University of Western Sydney, Parramatta, December.

Dodson, J. (2005) Is there a spatial mismatch between housing affordability and employment opportunity in Melbourne? Australian Housing and Urban Research Institute, Melbourne.

Dodson, J., Gleeson, B. ET AL. (2004) Transport disadvantage and social status: a review of literature and method. Research Monograph No. 5, Urban Research Program, Griffith University, Brisbane.

Fainstein, S., Gordon, I. ET AL. (1992) Divided Cities: New York and London in the Contemporary World. Oxford: Blackwell.

Fleay, B. (1995) The Decline of the Age of Oil: Petrol Politics: Australia's Road Ahead. Annandale, NSW: Pluto Press.

GleEson, B. and Randolph, B. (2001) Social planning and disadvantage in the Sydney context. Urban Frontiers Program, University of Western Sydney. 
Goodman, R. (2005) Sustainable urban form and the shopping mall: an investigation of retail provision in new housing subdivisions in Melbourne's growth areas. Paper presented to the Second Conference on the State of Australian Cities, Griffith University, Brisbane, NovemberDecember.

Hamilton, K. and Jenkins, L. (2000) A gender audit for public transport: a new policy tool in the tackling of social exclusion, Urban Studies, 37(10), pp. $1793-1800$.

HAmnetT, C. (1994) Social polarisation in global cities: theory and evidence, Urban Studies, 31(3), pp. 401-424.

Heinberg, R. (2004) Powerdown: Options and Actions for a Post-carbon World. Gabriola Island: New Society Books.

HiLls, J. (2001) Inclusion or exclusion? The role of housing subsidies and benefits, Urban Studies, 38(11), pp. 1887-1902.

Hine, J. and Mitchell, F. (2001) Better for everyone? Travel experiences and transport exclusion, Urban Studies, 38(2), pp. 319-332.

HoRIN, A. (2004) Carr's transport strategy goes off the rails, Sydney Morning Herald, 27 November.

How ARD, J. (2005) Radio Interview with Tanya Nolan, World Today (Australian Broadcasting Corporation) 26 September.

Huber, P. and Mills, M. P. (2004) The Bottomless Well: The Twilight of Fuel, the Virtue of Waste, and Why We Will Never Run Out of Energy. New York: Basic Books.

Industry Commission (1993) Public Transport: Draft Report, Vol. 2. Appendices. Canberra: Australian Government.

Johnson, L. and HerATH, S. (2004) Big roads, no transport: a report of the Goodna and Gailes community mapping for transport improvements study. Research Monograph No. 5, Urban Research Program, Griffith University, Brisbane.

Jong, G. C. DE., Biggiero, L. ET AL. (1998) Elasticity handbook for prototypical contexts: trace costs of private road travel and their effects on demand, including short and long term elasticities. European Commission Directorate-General for Transport, Brussels.

Kenworthy, J., Laube, F. et al. (1999) An International Sourcebook of Automobile Dependence in Cities. Boulder, CO: University Press of Colorado.

KING, A. (1994) Towards indicators of housing stress. Monograph Series No. 2, Department of Housing and Regional Development, Canberra.

Kunstler, J. H. (2005) The Long Emergency: Surviving the Converging Catastrophes of the Twenty-first Century. New York: Grove/Atlantic.

LEE, P. (1994) Housing and spatial deprivation: relocating the underclass and urban poor, Urban Studies, 31(7), pp. 1191-1209.
LuCAS, K. (Ed.) (2004) Running on Empty: Transport Social Exclusion and Environmental Justice. Bristol: The Policy Press.

LuCAS, P. (2005) Translink provides relief as petrol prices remain high. Media release, Minister of Transport, Brisbane.

Madden, J. F. (2003) The changing spatial concentration of income and poverty among suburbs of large US metropolitan areas, Urban Studies, 40(3), pp. 481-503.

MAHer, C. (1994) Residential mobility, locational disadvantage and spatial inequality in Australian cities, Urban Policy and Research, 12(3), pp. 185-191.

Maher, C., Whitelaw, J. et al. (1992) Mobility and locational disadvantage within Australian cities. Social Justice Research Program into Locational Disadvantage, Department of Prime Minister and Cabinet, Canberra.

Manning, I. (1984) Beyond Walking Distance: The Gains from Speed in Australian Urban Travel. Canberra: Australian National University Press.

Martin, R. W. (2001) Spatial mismatch and costly suburban commutes: can commuting subsidies help?, Urban Studies, 38(8), pp. $1305-1318$.

MCTIERnan, A. (2004) Speech to Sustainable Transport Coalition's 'Oil: Living with Less' Conference, Perth, West Australia, Minister of Transport and West Australian Government.

Mees, P. (2000a) A Very Public Solution: Transport in the Dispersed City. Melbourne: Melbourne University Press.

MeEs, P. (2000b) Rethinking public transport in Sydney. Issues Paper No. 5. Urban Frontiers Program, University of Western Sydney.

MeEs, P. (2002) The road lobby goes post-modern: deconstructing the 'feminist car'. Paper presented to the Institute of Australian Geographers Conference, Canberra, July.

MorRIS, J. (1981) Urban public transport, in P. N. Troy (Ed.) Equity in the City, pp. 21-49. Sydney: George Allen \& Unwin.

Morris, J., WANG, F. and Berry, M. (2002) Planning for public transport in the future: challenges of a changing metropolitan Melbourne. Papers of the 25th Australasian Transport Research Forum. Canberra, October.

MotorMouth (2005) Average Sydney unleaded petrol prices for past week (www.motormouth. com.au).

Murdoch, S. (2005) Petrol prices burn retailers, Courier-Mail, 4 November, p. 33.

Murphy, P. and WATson, S. (1994) Social polarization and Australian cities, International Journal of Urban and Regional Research, 18(4), pp. 573-590. 
National Housing Strategy (1991) The affordability of Australian Housing. Issues Paper No. 2, National Housing Strategy, Canberra.

Neutze, M. (1977) Urban Development in Australia. Sydney: George Allen \& Unwin.

Newman, P. (1991) Cities and oil dependence, Cities, August, pp. 170-173.

Newman, P. and Kenworthy, J. (1989) Cities and Automobile Dependence: A Sourcebook. Aldershot: Gower Technical.

Newman, P. and Kenworthy, J. (1999) Sustainability and Cities: Overcoming Automobile Dependence. Washington, DC: Island Press.

Newman, P., Kenworthy, J. and Lyons, T. (1985) Transport energy use in the Perth metropolitan region: some urban policy implications, Urban Policy and Research, 3(4), pp. 4-15.

Newman, P., Kenworthy, J. and Lyons, T. (1990) Transport energy conservation policies for Australian cities: strategies for reducing automobile dependence. Institute of Science and Technology Policy, Murdoch University, Perth.

O'Connor, K. and Healy, E. (2002) The links between labour marketsopes and housing markets in Melbourne. Australian Housing and Urban Research Institute, Melbourne.

RACV (Royal Automobile Club of Victoria) (2005) 2005 RACV vehicle operating costs. RACV, Melbourne.

Robinson, B. and Powrie, S. (2004) Oil depletion: the crucial factor in transport planning. Papers of the 27th Australasian Transport Research Forum. Adelaide, 29 September-1 October.

Senate Rural and Regional AfFairs And TRANSPORT COMmitTeE (2005) Interim report of Inquiry into Australia's future oil supply and alternative transport fuels. Australian Parliament House, Canberra.

SEU (Social ExClusion Unit) (2002) Making the connections: transport and social exclusion: interim findings from the Social Exclusion Unit. SEU, London.

SEU (2003) Making the Connections: Final Report on Transport and Social Exclusion. SEU, London.

Smith, A. (2004) Motorway design must learn from past mistakes, Sydney Morning Herald, 24 August.

Sustainable Transport Coalition (2005) Sustainable Transport Coalition website (http://www.stcwa.org.au/).
Taplin, J. H. E., Hensher, D. ET AL. (1999) Preserving the symmetry of estimated commuter travel elasticities, Transportation Research B, 33(3), pp. 215-232.

US DEPARTMENT OF ENERGY (2005) NYMEX light sweet crude oil futures prices, Contract 1 (http://www.eia.doe.gov/emeu/international/ Crude2.xls; accessed 7 January 2006).

WACQUANT, L. (1999) Urban marginality in the coming millennium, Urban Studies, 36(10), pp. 1639-1647.

WaLKs, R. A. (2001) The social ecology of the post-Fordist/global city? Economic restructuring and socio-spatial polarisation in the Toronto urban region, Urban Studies, 38(3), pp. 407-447.

WESSEL, T. (2000) Social polarisation and socioeconomic segregation in a welfare state: the case of Oslo, Urban Studies, 37(11), pp. 1947-1967.

Winter, I. and Stone, W. (1998) Social polarisation and housing careers: exploring the interrelationship of labour and housing markets in Australia. Working Paper No. 13, Australian Institute of Family Studies, Melbourne.

Wu, B. and HINE, J. (2003) A PTAL approach to measuring changes in bus service accessibility, Transport Policy, 1, pp. 307-320.

WulfF, M. and Evans, S. (1999) The spatial impacts of Commonwealth rent assistance on Australia's low-income households, in: M. WulfF and J. YATES (Eds) Australia's Housing Choices, pp. 101-112. Queensland: University of Queensland Press and the Australian Housing and Urban Research Institute.

WulfF, M. and Reynolds, M. (2000) Social polarisation and housing market change: a case study of Melbourne, 1986 to 1996. Paper presented to the Australian Population Association 10th Biennial Conference, 'Population and Globalisation: Australia in the 21st Century', Melbourne, November-December.

YATES, J. (2002a) Housing Implications of Spatial Social and Structural Change. Melbourne: Australian Housing and Urban Research Institute.

YATES, J. (2002b) The limits to choice in the private rental market, Just Policy, 25(March), pp. 32-48.

Zeibots, M. (2003) Before and after Sydney's M4 motorway: did it make the city more sustainable? Paper presented to the National Conference on the State of Australian Cities, University of Western Sydney, Parramatta, December. 